\title{
Mikrotremor, Deprem ve Yüzey Dalgalarının Çok Kanallı Analiz Yöntemi Kayıtları Kullanılarak Zemin Özelliklerinin Belirlenmesi: AFAD Kampüsünden Örnek Bir Uygulama
}

\author{
Erkan Ateş ${ }^{1, *}$ \\ ${ }^{1}$ T.C. Içişleri Bakanlığı, Afet ve Acil Durum Yönetimi Başkanlığı, Deprem Dairesi Başkanlığı, Ankara.
}

\section{Özet}

Zemin büyütmesinin belirlenmesinin en geçerli yolu kuvvetli yer hareketi kayıtlarının analizlerinin kullanılmasıdır. Ankara AFAD kampüsü içerisinde yer alan deprem gözlem istasyonu 2014 yılında kurulmuştur. Çalışma alanı içerisinde bulunan bölgede Ankara Bilkent Şehir Hastanesi, Sağlık Bakanlığl, Tarım ve Orman Bakanlı̆̆l, Ticaret Bakanlığl gibi birçok resmi kurum bulunmaktadır. Deprem istasyonun kurulduğu günden bu güne kadar 22 adet deprem kaydı kaydedilmiştir. İstasyonun bulunduğu zeminin üst 30 ve 50 metre ortalama kayma dalga hızı hesaplanması için yüzey dalgalarının çok kanallı analizi (MASW) ölçümü yapılmıştır. İstasyonun kaydettiği değişik fay zonlarında meydana gelen farklı büyüklük ve uzakllklarda 14 adet deprem kaydı tek istasyon yöntemine göre yatay/düşey oran tekniği kullanılarak yorumlanmış ve zemine ait büyütme faktörü ve hakim titreşim frekansı hesaplanmıştır. Deprem kayıtları dıșında CMG-6TD sismometre ile 4 saat mikrotremor ölçümü yapılmış, alınan ölçümler tek istasyon yöntemine yatay/düsey spektral oran tekniğine göre değerlendirilmiştir. Yapılan MASW, mikrotremor ve deprem kayıtlarının sonuçları karşılaş̧ırılmış, yerin dinamik özellikleri incelenmeye çalışılmıştır. Deprem ve mikrotremor kayıtlarının analizleri üzerinden sonuçlara bakıldığında; büyütme faktörü ve hakim frekansların birbirine çok yakın olduğu, kayma dalga hızından hesaplanan zemin sınıfi ile uyumlu olduğu görülmüştür.

\section{Anahtar Sözcükler}

Mikrotremor, Deprem, Büyütme, MASW, Hakim Frekans

\section{Determination of Soil Properties by Using Multi-Channel Analysis Method Records of Microtremor, Earthquake and Surface Waves: A Sample Implementation from AFAD Campus}

\begin{abstract}
The most valid way to determine the soil amplification is to use the analysis of strong ground motion records. The Earthquake Observation Station located in Ankara AFAD campus was established in 2014. There are many official institutions such as Ankara Bilkent City Hospital, Ministry of Health, Ministry of Agriculture and Forestry, and Ministry of Trade within the working area. Since the earthquake station was established, 22 earthquake records have been registered. Multichannel analysis of surface waves (MASW) was measured to calculate the average shear wave velocity of the upper 30 and 50 meters of the soil where the station was located. 14 earthquake records of different magnitudes and distances occurring in different fault zones recorded by the station were interpreted using the horizontal / vertical ratio technique according to the single station method, and the amplification factor and dominant vibration frequency of the soil were calculated. Apart from the earthquake records, 4 hours of microtremor measurements were made with the CMG-6TD broadband seismometer, and the measurements were evaluated according to the single station method and the horizontal / vertical spectral ratio technique. The results of MASW, microtremor and earthquake records were compared, and the dynamic properties of soil were studied. According to the results obtained from the analysis of earthquake and microtremor records, it has been observed that the amplification factor and predominant frequencies are very close to each other, compatible to the soil class calculated by using the shear wave velocity.
\end{abstract}

$\underline{\text { Keywords }}$

Microtremor, Earthquake, Amplification, MASW, Dominant Frequency

\section{Giriş}

Bir deprem meydana geldiğinde kaynaktan yayılan sismik dalgalar yollarının bir bölümünü yer kabuğunu oluşturan sert anakaya içinde son aşaması ise kayaya göre yumuşak olan yer tabakaları içerisinde geçirirler (Yalçınkaya 2010). Deprem dalgaları yerüstünde saniyeden dakikalara varan titreşim üretirler. 
Titreşim süresi depremin büyüklüğüne, merkez üssüne olan uzaklığına ve zemin özelliklerine göre değişiklik gösterecektir. Depremin dalgasının genlik değeri alüvyon zeminlerde yüksek olacakken, kayada daha az olacaktır. Bazı yönetmelikler zemin özelliklerinin kayma dalgası hızlarına göre tanımlamıştır. Türk Deprem Yönetmeliğine göre ilk 30 m kayma dalgası hızı 180 m/s'den 1500 m/s'ye kadar sınıflara ayrılmıştır (TBDY 2018). Birçok araştırmacı zemini ve kayayı kayma dalgasına göre sınıflandırmışlardır. Örneğin Ambraseys kayma dalga hızı $<760$ m/s olan alanları zemin olarak (Ambraseys vd. 1996), Nath (2007) ise kayma dalga hızının 3000 m/s'den yüksek olduğu alanları sismik anakaya olarak tanımlamıştır .

Zemin dinamik özelliklerini belirlemenin en geçerli yolu kuvvetli yer hareketi kayıtlarının incelenebilmesi ile mümkündür. Zeminler bir süzgeç gibidir. Deprem dalgaları yer yüzeyine ulaştıklarında zemin özelliklerine bağlı olarak bazı frekans içeriğindeki dalgaları sönümlenirken bazı frekanstaki dalgaların genlikleri artmaktadır. Bu genlik artışına zemin büyütmesi denir. Zemin büyütmesinin belirlenmesin de en geçerli yol deprem kayıtlarının incelenmesidir. Zemin büyütmesinin belirlenmesinde kullanılan yöntemlerden bir tanesi yatay/düşey spektral oran (HVSR) yöntemidir (Nakamura 1989; Lermo ve Chavez 1993). Bu yöntem tek istasyon kullanılması ve referans (anakaya) istasyonuna gerek duyulmaması sebebi ile oldukça sık olarak kullanılmaktadır (Bonilla vd. 1997; Gok vd. 2014; Pamuk 2019). Yöntemin esası yatay bileşenlerin düşey bileşene oranlanması prensibine dayanmaktadır. İvmeölçer kayıtlarına uygulanan HVSR yöntemi ülkemizin değişik bölgelerinde zemin etkisinin belirlenmesinde sıklıkla kullanılmaktadır. Bursa, Kocaeli ve Erzurum illerinde kurulu bulunan ivmeölçer istasyonlarını kullanılarak zemin etkisini belirlenmiştir (Yalçınkaya 2005; Ateş ve Uyanık 2019; Ozer 2019).

Zemin büyütme faktörünün belirlemenin bir diğer yöntemi mikrotremor ölçümleri yaparak analiz edilmesidir. Bu yöntem hızlı veri toplanması ve deprem kaydı olmadan zemin etkisini belirlendiğinden mühendislik çalışmalarında yaygın olarak kullanılmaktadır. Ülkemizde Kocaeli ve İzmir ilinde mikrotremor ölçümleri alınarak zemin etkisi belirlenmiştir (Tunçel vd. 2019; Livaoğlu 2015). İzmir ilinde ise mikrotremor, mikrogravite ve MASW analizleri sonucunda 3 boyutlu zemin yapısı incelenmiştir (Pamuk vd. 2018). Van ilinde ise mikrotremor, sondaj verileri ve yüzey dalgalarının çok kanallı analiz yöntemleri karşılaştırılmıştır (Akkaya ve Özvan 2019). Kocaeli ilinde ise mikrotremor ve gravimetrik yöntemlerle incelenmiştir (Ozalaybey vd. 2011). İzmir ilinde zeminlerin büyütme kavramı üzerine çalışmalar bulunmaktadır (Özdağ vd. 2015). Yine İzmir Menemen ovasının staratigrafik yapısını mikrogravite ve pasif sismik yöntemlerle incelenmiş ve deprem etkisi altında davranışı incelenmeye çalışılmıştır (Özdağ ve Gönenç 2020).

Bu çalışmada AFAD kampüsü içerisinde konumlandırılmış deprem cihazının kaydettiği 14 adet büyüklüğü 3,0 ve 4,8 arasında değişen farklı uzaklıktaki ve farklı fay zonlarından meydana gelen deprem kayıtları kullanılmıştır. Kullanılan depremlerin istasyona uzaklıkları 13-92 km mesafelerdedir. Deprem kayıtlarına yatay/düşey spektral oran (HVSR) yöntemi uygulanarak zeminin dinamik özellikleri bulunmaya çalışılmıştır. Aynı zamanda deprem istasyonunda CMG6TD sismometre cihazı ile 4.5 saat mikrotremor kaydı alınmış ve yatay/düşey spektral oran yöntemi kullanılarak analiz edilmiştir. Deprem ve mikrotremor kayıtlarına ilave olarak aynı noktada MASW yöntemi ile bir profil üzerinde veri toplanmış ve zeminin ilk 50 metreye kadar bir boyutlu yer altı hız kesiti elde edilerek diğer yöntemlerle elde edilen sonuçlar ile karşılaştırılmıştır.

\section{2. Çalışma Alanı ve Kullanılan Yöntemler}

\section{1. Çalışma Alanı Deprem Etkinliği}

Türkiye'nin başkenti olan Ankara, İç Anadolu bölgesinde yer alır ve dört tarafı kuzeyden sağ yanal doğrultu atımlı Kuzey Anadolu fayı, güneydoğudan Seyfe fayı, güneyden Tuz Golü fayı (Holosen Fayı), doğudan Kuvaterner faylardan olan Çankırı ve Karakeçili fayları tarafından çevrelenmiş durumdadır (Emre vd. 2013). Şekil 1'de görüleceği üzere Ankara kent merkezi içerisinde içerisinden geçen aktif bir fay hattı bulunmamaktadır. Ankara kent merkezi adı gecen bu faylara 60 - $100 \mathrm{~km}$ uzaklıktadır. Şekil 1'de çalışma alanına $120 \mathrm{~km}$ çevresinde aletsel dönemden (1900) günümüze (2020) meydana gelmiş moment büyüklüğü 4,0'dan büyük depremler gösterilmiştir.

Şekil 1'de gösterilen depremler AFAD Deprem Dairesi Başkanlığı tarafından düzenlenen deprem kataloğundan alınmıştır. Görüleceği üzere 6,9 ve 7,3 büyüklüğünde bulunan iki adet deprem Kuzey Anadolu Fay zonu üzerinde gerçekleşmiştir. Bunlardan 7,3 büyüklüğünde ve 1944 yılında meydana gelen Gerede depremi, bir diğeri 6,9 büyüklüğünde meydana gelen Kurşunlu depremidir (Eker vd. 2015). Büyüklüğü 6,0 olan 06.06.2000 y1lında meydana gelen Çankırı Orta depremi Dodurga fay zonu üzerinde meydana gelmiştir. Çalışma sahasına yakın Bala bölgesinde meydana gelen 5,0'dan büyük depremler 31.07.2005, 20.12.2007 ve 27.12.2007 yılında meydana gelen Bala depremleri Karakeçili Fay Zonu üzerinde yoğunlaşmıştır. Bu fay zonu doğrultu atımlı bileşenli yeni eğimli atımlı normal fay olarak tanımlanmıştır (Türkmen ve Özkul 1999; Saraç 2003).

Büyüklüğü daha küçük depremlerin büyük çoğunluğu Çankırı Fayı, Dodurga Fayı ve Bala fayı üzerinde yoğunlaştığı görülmektedir. Çankırı Orta ve Ankara Bala ilçeleri civarındaki meydana gelen deprem kümelenmeleri 06.06.2000 tarihinde meydana gelen Çankır1-Orta ve 31.07.2005, 20.12.2007 ve 27.12.2007 tarihlerinde meydana gelen depremlerin artçı şokları sebebiyledir. 


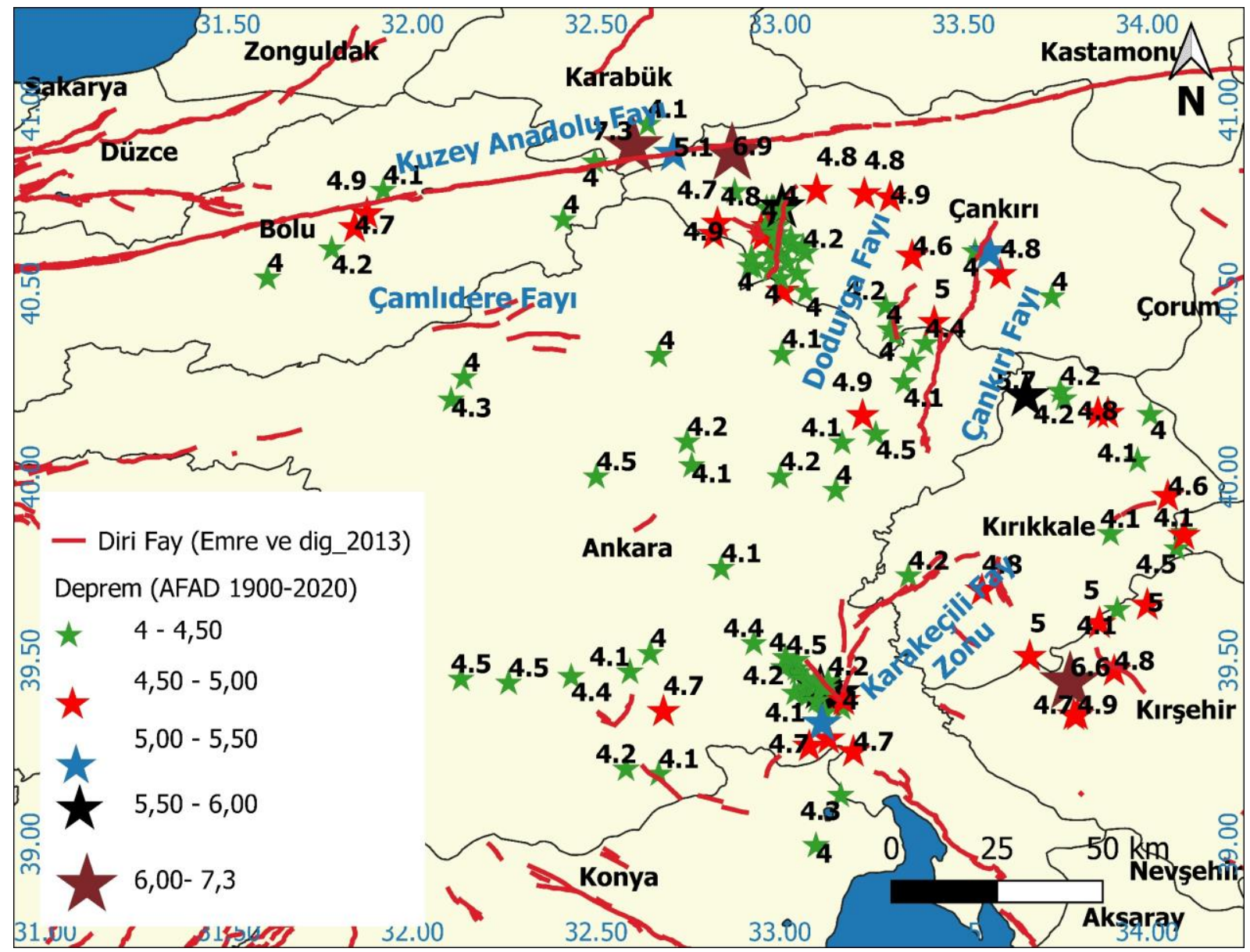

Şekil 1: Ankara çevresinde meydana gelmiş büyüklügü>4,0 üzerinde depremler (AFAD 1900-2020)

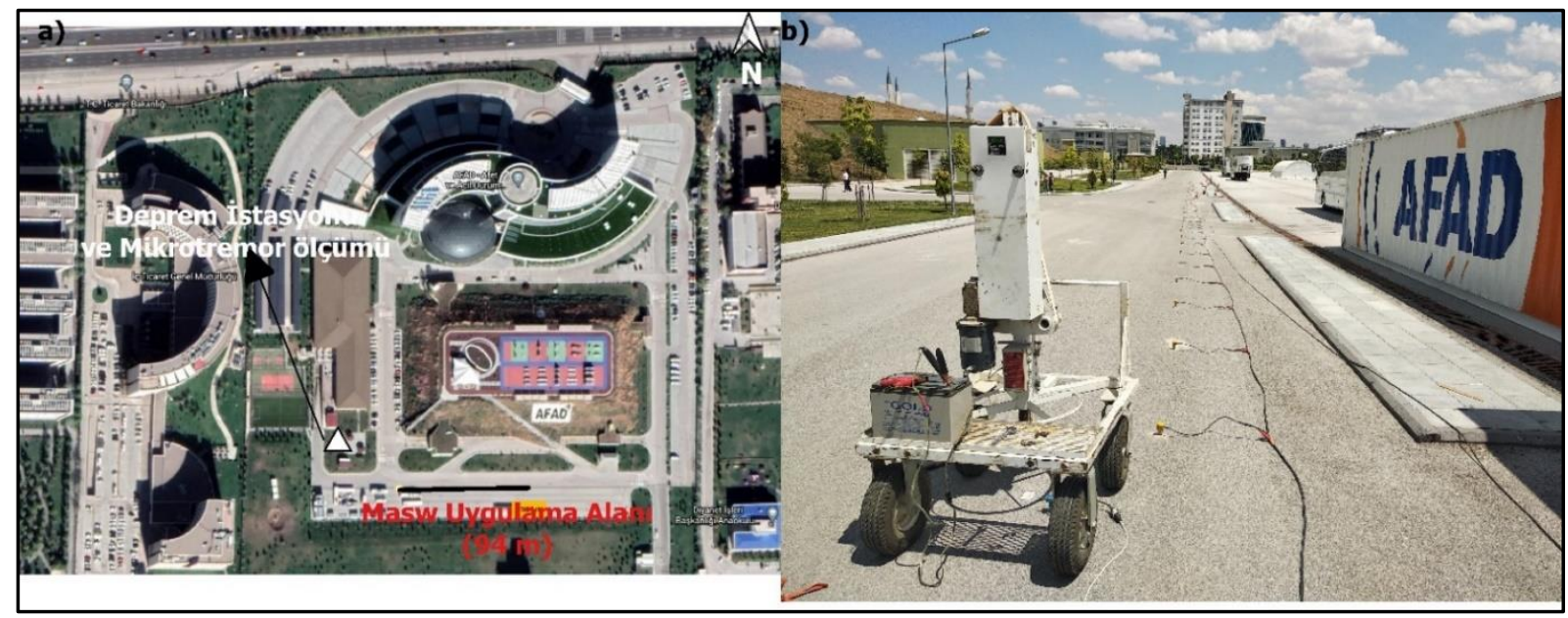

Şekil 2: a) Çalışma alanı uydu görüntüsü ve ölçüm alanları, b) MASW serim alanı fotoğrafı

\section{2. Çalışma Alanı Genel Jeolojisi}

MTA tarafından araştırmacıların hizmetine sunulan Türkiye Yerbilimleri Harita Görüntüleyici ve Çizim Editörü (Akbaş vd. 2011) kullanılarak çalışma alanı jeolojik birimleri sayısallaştırılmıştır (Şekil 3). Bu haritaya göre Ankara ilinin batısında kentin gelişme yönü üzerinde bulunan alanlardaki jeolojik yapılar genellikle Üst Pliyosen çökelleri ve Kuvaterner'e ait birimlerden oluşmaktadır. Ankara İli’nin ilk yerleşimleri alanlarından birisi olan Altındağ İlçesinde AltOrta Miyosen yaşlı Volkanitler yüzeylenmektedir. Keçiören ve Mamak ilçelerinde ise "Mamak Formasyonu" olarak tanımlanan Miyosen yaşlı volkanik kayalar gözlenir. 
Çankaya ilçesinin; Dikmen, Karakusunlar ve Yıldızevler Mahallesi gibi eski yerleşim alanları Triyas yaşlı kumtaşı, bazik volkanikler üzerine, Kolej, Maltepe, Ümitköy ve Üniversiteler Mahallesi gibi yeni yerleşim alanları ise "Ankara Kili” olarak adlandırılan Pliyosen yaşlı karasal kırıntılar üzerine konumlanmıştır.

Ankara'nın diğer büyük ilçesi olan Yenimahalle ilçesinin büyük bir bölümü Pliyosen yaşlı karasal kırıntılar üzerine konumlanmış olup ilçe merkezinin kuzeyinde yer alan mahalleleri Miyosen yaşlı birimlerden oluşmaktadır. Sincan ilçe merkezi Kuvaterner yaşıı alüvyon üzerinde yer almaktadır. Etimesgut ilçesi ve kuzey batısındaki Eryaman ve Şeker Mahallesi gibi yerleşim alanları da Kuvaterner yaşlı alüvyon üzerinde konumlanmıştır.

Ankara ili merkezinde Şekil 3 'te göründüğü üzere Gazi Üniversitesi ve AFAD tarafından kurulan 8 adet kuvvetli yer hareketi istasyonu bulunmaktadır. Bu istasyonlardan 7 adeti "GZ” kodu ile Gazi Üniversitesi'ne aittir. İstasyonlara ait kayma dalga hızları haritada gösterilmiştir. Bu istasyonlardan bir tanesi Volkanit olarak tanımlanan kaya birimler üzerine kurulmuş olup ilk 30 metre kayma dalga hızı 728 m/s'dir. Diğer ilçelerde bulunan istasyonlar ise Kuvaterner çökeller ve karasal kırıntılar üzerine konumlandırılmıştır. Zayıf zeminde konumlanmış bu istasyonların ilk 30 metre kayma dalga hızları $200 \mathrm{~m} / \mathrm{s}$ ile $340 \mathrm{~m} / \mathrm{s}$ arasında değişmektedir.

Bu çalışmanın konusu olan Üniversiteler Mahallesi AFAD kampüsü içerisinde yer alan kuvvetli yer hareketi kayıt istasyonu Pliyosen yaşlı karasal kırıntılar üzerine konumlanmıştır (Akbaş vd. 2011).

Çalışma alanında daha önce yapılmış temel zeminin yapısal durumunun ortaya konması ve zeminin mühendislik parametreleri ile yeraltı suyunun yapıya etkisinin araştırılması amacıyla özel bir firma tarafından 9 noktada yapılan derinlikleri 20 metre derinlikte sondaj kuyusu açılmıştır. İnceleme alanında temel jeolojik birim; az kumlu plastisitesi yüksek kil (CH-CL) olarak tespit edilmiştir. Yapılan sondajlarda 3 adet kuyuda $18 \mathrm{~m}$ ve 20 m derinliklerde suya rastlanmıştır. Yapılan Standart Penetrasyon Deneyinde N30 değeri 20 metreye kadar 15-50 arasında değişmektedir. Çalışma alanında yapılan sondajlara ait karot numune örneği şekil 4'te gösterilmiştir. Alınan karot numunelerinde birimin 20 metreye kadar değişmediği gözlenmiştir.

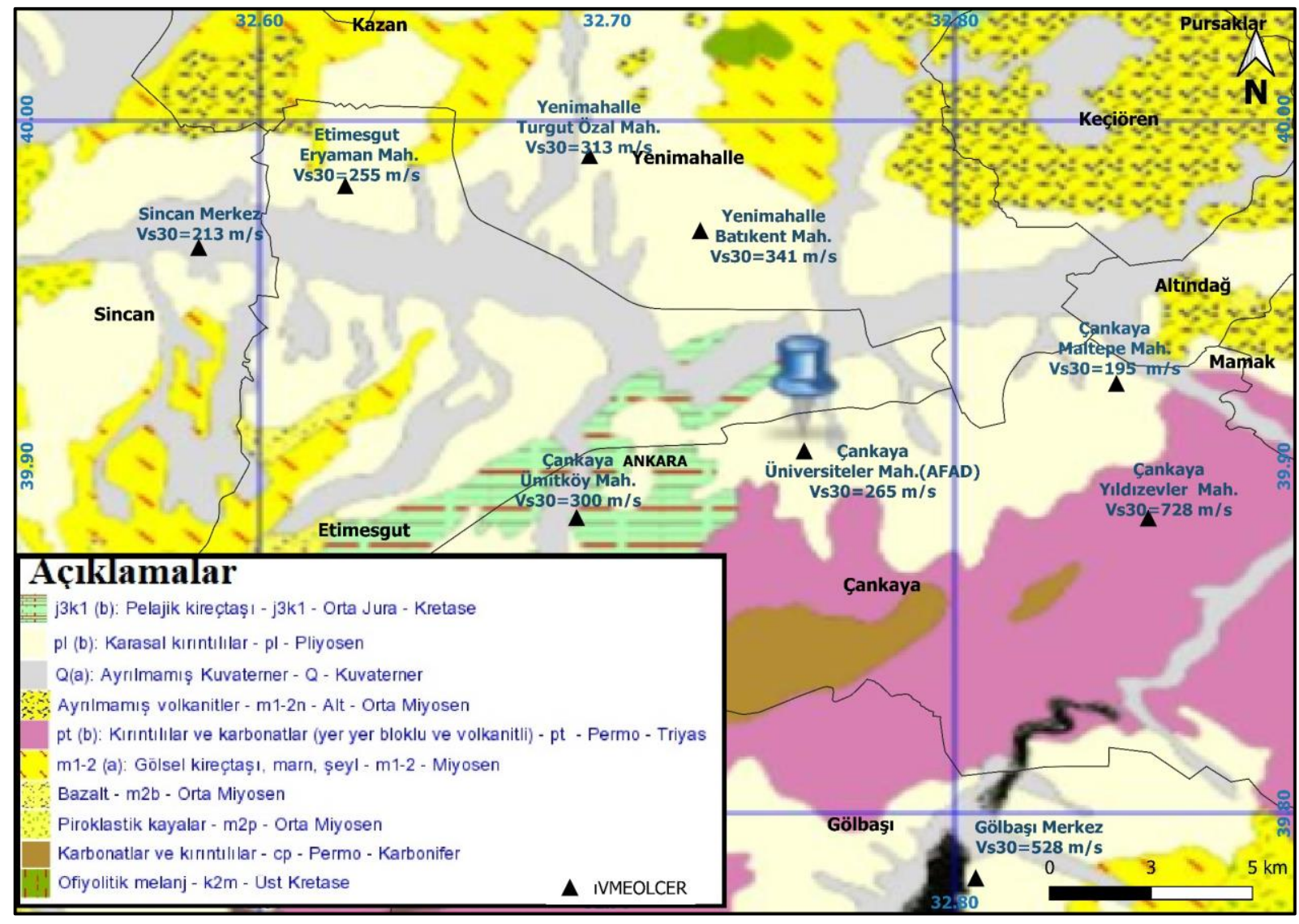

Şekil 3: Çalışma alanı genel jeoloji haritası (Akbaş vd. 2011) 


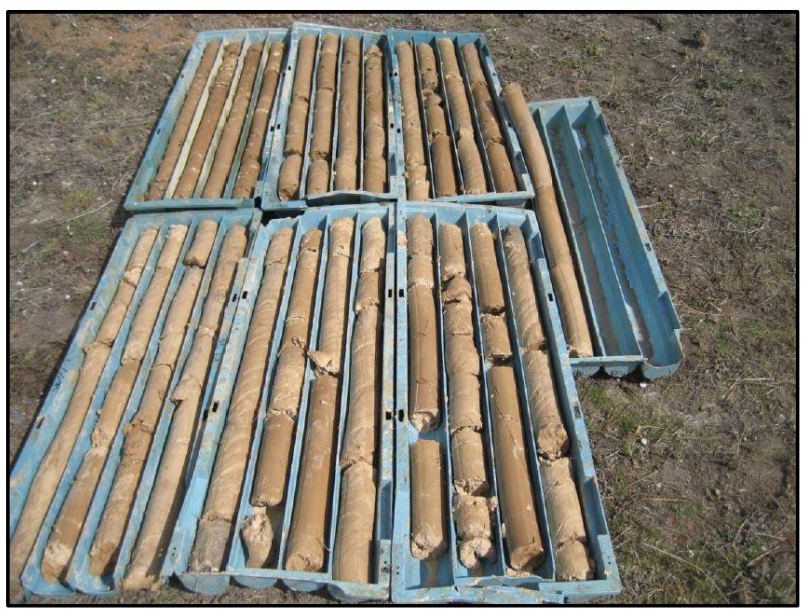

Şekil 4: Çalışma alanından alınan karot numune örnekleri

\subsection{MASW Yöntemi ve Ölçümleri}

Yüzey dalgalarının çok kanallı analizi için MASW yöntemi (Park vd. 1999) kullanılmaktadır. Kayma dalga hızları yüzey dalgalarının dispersiyon eğrisinin analizinden hesaplanmaktadır. Yöntemde sağlıklı veri toplanılması için uygun veri toplamak ve yeterli miktarda enerji oluşturmak gerekmektedir.

Toplanan MASW ölçümüne faz hızı- frekans dönüşümü yapılır. Bu işlem sonrasında dispersiyon eğrisi hesaplanır, ölçülen veri ile yeraltının modelinin dispersiyon eğrisi çakıştırılır (Ters Çözüm). Ters çözüm sonucunda yeraltı hız modeli oluşturulur.

Oluşturulan yeraltı hız modelinden elde edilen kayma dalga hızları kullanılarak zemin hakim periyodu eşitlik 1 den hesaplanır. Eşitlik 1 deki H derinliği kayma dalga hızına bağlı 30 ya da $50 \mathrm{~m}$ seçilir. İlk $30 \mathrm{~m}$ içerisinde tabakanın kayma dalga hızı $500 \mathrm{~m} / \mathrm{s}$ 'den yüksek ise derinlik $(\mathrm{H})=30 \mathrm{~m}$ alınır tersi olması durumunda derinlik $(\mathrm{H})=50 \mathrm{~m}$ olarak kullanılmalıdır (Uyanık 2015).

$T_{\text {zemin }}=\left(4 \times \frac{h_{1}}{v_{s 1}}\right)+\left(4 \times \frac{h_{2}}{v_{s 2}}\right)+4 \times\left(\frac{h-\left(h_{1}+h_{2}\right.}{v_{s 3}}\right)$

\subsection{Yatay/Düşey Spektral Oran Yöntemi (HVSR)}

Yatay/Düşey Spektral Oran (HVSR) yönteminde esas düşey bileşenin zemin büyütmesinden etkilenmediği görüşüyle yatay bileşenlerinin genlik spektrumlarının ortalamasının düşey bileşen spektrumuna oranlanmasına dayanır (Nakamura 1989; Lermo ve Chavez 1993). Bu şekilde zemin hakim frekansı ve büyütme faktörü belirlenebilir.

$\mathrm{Bu}$ yöntem deprem ve mikrotremor verilerine başarı ile uygulanabilmektedir. Eşitlik 2'de gösterildiği üzere yatay bileşen spektrumlarının bileşkelerinin düşey bileşene oranlanarak hakim frekans ve büyütme faktörü değerleri bulunabilir. Eşitlik 2'de verilen $Y b$ yatay bileşen genlik spektrumlarının bileşkesini $D b$ düşey bileşen genlik spektrumunu $Z h$ transfer fonksiyonunu göstermektedir.

$Z_{h}=\left(\frac{Y_{b}}{D_{b}}\right)$

\section{Bulgular}

\subsection{Masw Yöntemi sonuçları}

İvmeölçer istasyonunun bulunduğu zeminin kayma dalga hızları ve bu hızlar kullanılarak hesaplanan zemin hakim titreşim periyodu, zemin sınıfının belirlenmesi amacıyla yapılan MASW çalışmasında 48 kanallı bir Geode marka kayıt sistemi, enerji kaynağı olarak 50 kilogram ağılık düşürme sistemi kullanılarak kayıt alınmıştır (Şekil 2). Kullanılan jeofon aralıkları $2 \mathrm{~m}$, serim uzunluğu 94 metredir. Şekil 2'de ölçüm alanı ve krokisi gösterilmiştir. Kayıtlarda yığma işlemi yapılmış olup 4 adet vuruş yapılmıştır. Kayıt uzunluğu 2 sn'dir. Şekil 5 'te arazide alınan ham kayıt, dispersiyon eğrisi ve ters çözüm sonucu bulunan yer hız yapısı görülmektedir.

Çalışmada etkin derinlik 50 metre olarak belirlenmiş buna bağlı olarak zeminin ilk 50 metre bir boyutlu kayma dalga hız profili oluşturulmuştur. Görüleceği üzere kayma dalgası hızı 26 metreye kadar olan tabakalar benzer kayma dalga hızına sahiptir. Bu tabakaların 26 metreye kadar değişmediği sonucu çıkmaktadır. 
Yapılan çalışmada ilk 30 metre ortalama kayma dalga hızı $265 \mathrm{~m} / \mathrm{s}$ hesaplanmış olup, bu değer tablo 1'de yer alan ve ilk 30 metre kayma dalga hız değerleri kullanılarak oluşturulan yeni deprem yönetmeliği zemin sınıflama tablosuna göre D grubu zemin olarak sınıflandırılmıştır. Zeminin ortalama ilk $50 \mathrm{~m}$ kayma dalga hızı ortalaması ise $294 \mathrm{~m} / \mathrm{s}$ 'dir. Zeminde 50. metrede ulaşılan kayma dalga hızı $374 \mathrm{~m} / \mathrm{s}$ olarak hesaplanmıştır. Bir boyutlu kayma hız dalga profilinden görüleceği üzere 50 metre kalınlığa aynı jeolojik birimde (kil) olduğu düşünülmektedir. Ters çözüm RMS sonucu \% 5 'in altındadır. $\mathrm{Bu}$ ölçülen ile matematiksel model sonucunun birbiri ile uyumlu olduğunu göstermektedir. Yerinde yapılan sondaj çalışması ile de sismik çalışmanın sonuçları birbiri ile uyumlu olduğu gözlenmiştir. Zemin hakim periyodunun $50 \mathrm{~m}$ etkinliğe kadar yapılan hesaplamada $0,7 \mathrm{sn}(1.42 \mathrm{~Hz})$ olarak hesaplanmıştır.

Zeminin kayma dalga hızı zeminin büyütmesini belirlemek için kullanışlı bir yöntemdir. İlk 30 metre ortalama kayma dalgası kullanılarak hesaplanan ampirik bağıntılar kullanılarak göreceli zemin büyütme hesaplanabilmektedir. Hesaplanan ilk 30 metre ortalama kayma dalgasına göre göreceli zemin büyütme değerleri 2,4 (Midorikawa 1987) ve 2,6 (Borcherd vd. 1991) olarak hesaplanmıştır.

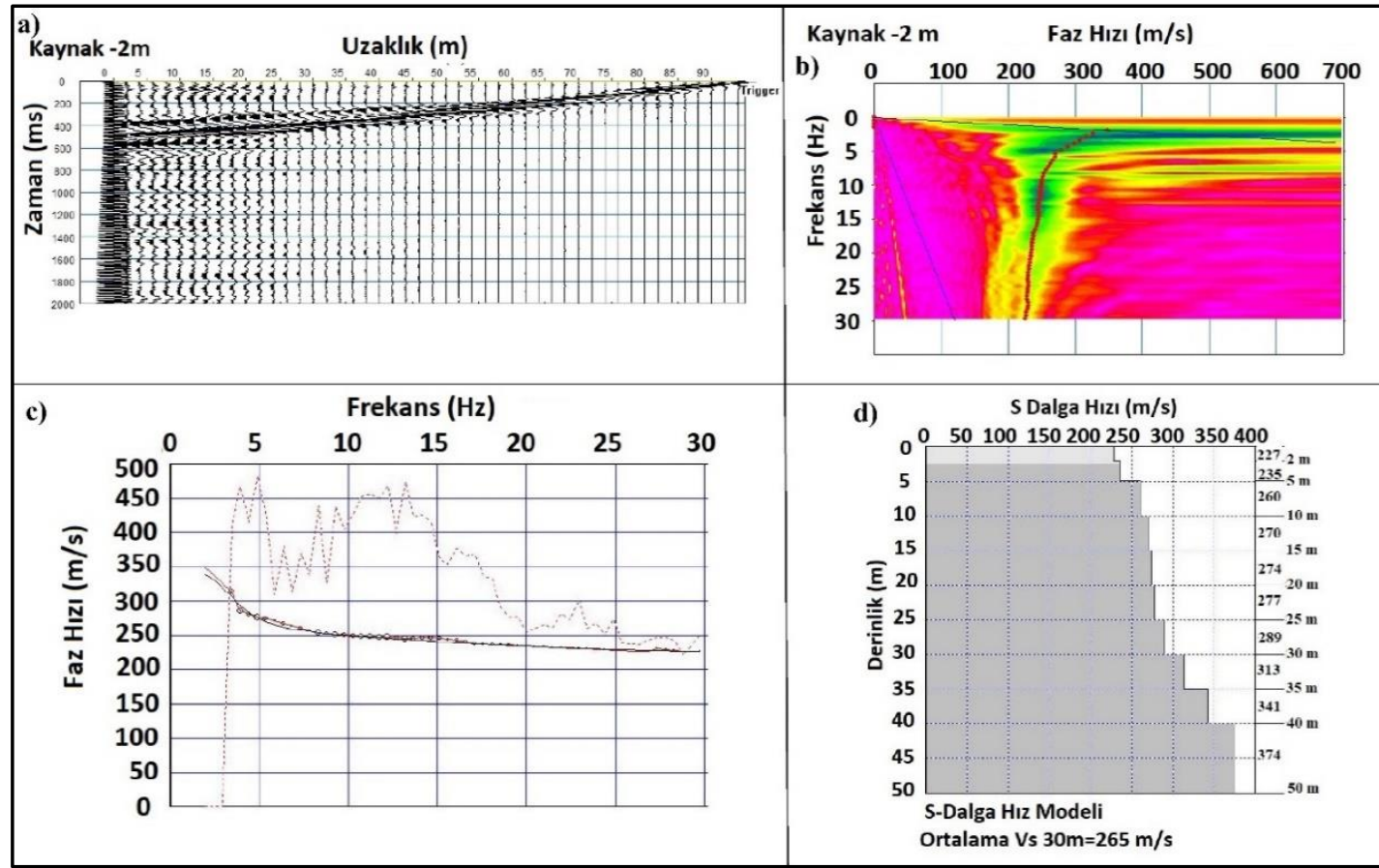

Şekil 5: a) Araziden alınan ham kayıt, b) dispersiyon eğrisi, c) ters çözüm, d)yeraltı hız kesiti

Tablo 1: Türk Deprem Yönetmeliği zemin sınıflama tablosu (TDY 2018)

\begin{tabular}{|c|c|c|}
\hline $\begin{array}{l}\text { Yerel Zemin } \\
\text { Sinıfı }\end{array}$ & Zemin Cinsi & $\begin{array}{c}\text { Üst } 30 \text { metrede } \\
\text { ortalama Vs }(30),(\mathrm{m} / \mathrm{s})\end{array}$ \\
\hline ZA & Sağlam, sert kayalar & $>1,500$ \\
\hline $\mathrm{ZB}$ & Az ayrışmış, orta sağlam kayalar & $760<$ Vs $(30) \leq 1500$ \\
\hline $\mathrm{ZC}$ & $\begin{array}{l}\text { Çok sıkı kum,çakıl ve sert kil tabakaları veya } \\
\text { ayrışmış, çok çatlaklı zayıf kayalar }\end{array}$ & $360<\operatorname{Vs}(30) \leq 760$ \\
\hline $\mathrm{ZD}$ & $\begin{array}{l}\text { Orta sık1-sıkı kum, çakı1 veya çok katı kil } \\
\text { tabakaları }\end{array}$ & $180 \leq \mathrm{Vs}(30) \leq 360$ \\
\hline $\mathrm{ZE}$ & $\begin{array}{l}\text { Gevşek kum, çakıl veya yumuşak-katı kil } \\
\text { tabakaları veya PI>20 ve w\% } \% 40 \text { koşullarını } \\
\text { sağlayan toplamda } 3 \text { metreden daha kalın } \\
\text { yumuşak kil tabakası içeren profiller }\end{array}$ & Vs $(30)<180$ \\
\hline $\mathrm{ZF}$ & $\begin{array}{c}\text { Sahaya özel araştırma ve değerlendirme } \\
\text { gerektiren zeminler }\end{array}$ & \\
\hline
\end{tabular}




\subsection{HVSR Yöntemi Sonuçları}

\subsubsection{Deprem Kayıtlarına Uygulanan HVSR Yöntemi}

Kullanılan Depremler: İvmeölçer istasyonunun yer yapısı ve büyütme faktörünü belirlemek amacıyla 14 adet deprem verisi kullanılmıştır (Şekil 6). 2015-2021 yılları arasında kayıt edilen depremlerin büyüklükleri 3,0 ile 4,8 arasında, merkez üssünün istasyona olan uzaklığı ise 13 ila $92 \mathrm{~km}$ arasında değişmektedir. Depremlerin konumları Şekil 6'da, oluş zamanları, depremlere ait bilgiler ve istasyona olan uzaklıkları Tablo 2'de gösterilmiştir. Kayıtlar GMSPLUS (100 HZ) marka ivmeölçer tarafından kaydedilmiştir. Kayıtlar 0,01 saniye aralıklar ile sayısallaştırılmıştır. Kullanılan kayıtların tamamı https://tadas.afad.gov.tr adresinden indirilmiştir.

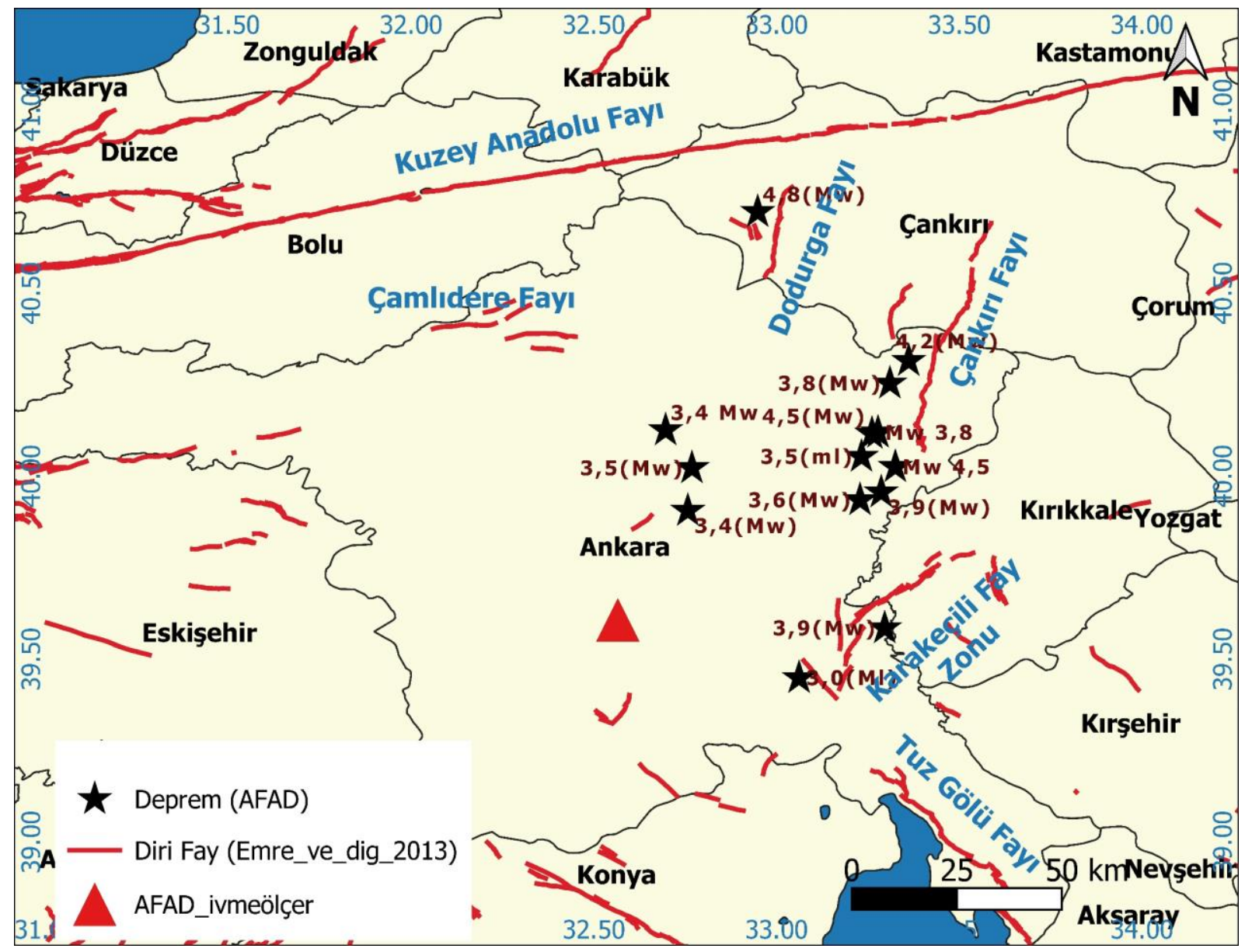

Şekil 6: HVSR analizde kullanılan depremlerin konumları

Şekil 6'da görüleceği üzere depremlerden büyüklükleri 4,2 ve 3,8 olan iki deprem Çankırı Fay zonundan büyüklüğü 3,9 ve 3,0 olan iki deprem Karakeçili Fay zonu üzerinde gerçekleşmiştir. Büyüklükleri 3,0 ve 3,9 arasında değişen 4 adet deprem kümelenmesi ise Elmadağ çevresinde yoğunlaşmıştır. Tablo 2'de görülen ve istasyona yakın uzaklıkta (13-28 km) bulunan depremler küçük ölçekli gömülü faylardan meydana geldiği düşünülebilir. Özellikle 20190825 tarihli deprem Yenimahalle ilçe merkezlidir ve merkez ilçelerinde şiddetli olarak hissedilmiştir. Bu depremde en yüksek ivme değeri Doğu-Batı yönünde 16,60 cm/s2'dir. 2021 yılı ocak ayında meydana gelen 4,5 büyüklüğünde meydana gelen Kalecik ilçesinde meydana gelen deprem Ankara merkez ilçelerinde hissedilmiştir.

Veri İşlem ve Sonuçlar: Depremde kaydedilen ivme kayıtları ile büyütme faktörü ve baskın frekans hesaplamada iki adet yatay bileşen spektrumu birleştirilerek düşey bilesene spektrumuna oranlanmıştır. Yön bağımlılığından kurtulmak için 2 adet yatay bileşen birleştirilmiştir. Depremlere ait bilgiler tablo 2'de verilmiştir. Kaydedilen her bir deprem kaydı için S dalga fazının 2 sn önünden başlayarak toplam 20 sn'lik pencere kullanılmıştır. Seçilen S fazına filtre uygulanmış (Bant geçişli 0.1-25 Hz) ve veri baş ve sonundan kosinüs törpü (\%5) yapılmıştır. Her bir pencere için Hızlı Fourier Dönüşümü (FFT) uygulanarak her bir bileşene ait genlik spektrumları elde edilmiştir. Elde edilen spektrumlara ise bant genişliği $b=40$ seçilerek (Konno ve Ohmachi 1998) yuvarlatma uygulanmıştır. Son aşamada ise yatay bileşen spektrumlarının düşey bileşen spektrumuna oranlanmasıyla HVSR değerleri elde edilmiştir. Örnek bir deprem kaydı ve seçilen S fazı Şekil 7'de gösterilmiştir. 
Tablo 2: Çalışma alanında uygulanan HVSR analizde kullanılan depremlere ait bilgiler

\begin{tabular}{|c|c|c|c|c|c|}
\hline Tarih_Saat (GMT) & Enlem & Boylam & Buyukluk & $\begin{array}{c}\text { Derinlik } \\
(\mathbf{k m})\end{array}$ & $\begin{array}{c}\text { Uzaklık } \\
\text { (km) }\end{array}$ \\
\hline 20150511_23:40 & 39,9558 & 33,2863 & $3,9(\mathrm{Mw})$ & 6 & 41 \\
\hline 20150617_22:06 & 39,5846 & 33,2958 & $3,9(\mathrm{Mw})$ & 5 & 58 \\
\hline 20151216_22:15 & 39,9346 & 33,2283 & $3,6(\mathrm{Mw})$ & 7 & 46 \\
\hline 20160529_01:42 & 39,4485 & 33,0615 & $3,0(\mathrm{Ml})$ & 12 & 56 \\
\hline 20160802_19:30 & 40,3150 & 33,3615 & $4,2(\mathrm{Mw})$ & 12 & 70 \\
\hline 20161126_04:52 & 40,2533 & 33,3100 & $3,8(\mathrm{Mw})$ & 13 & 61 \\
\hline 20190628_10:55 & 40,0533 & 33,2323 & $3,5(\mathrm{Ml})$ & 14 & 44 \\
\hline 20190820_19:11 & 40,1486 & 32,7068 & $3,4(\mathrm{Mw})$ & 8 & 28 \\
\hline 20190825_18:42 & 40,0220 & 32,7683 & $3,5(\mathrm{Mw})$ & 7 & 13 \\
\hline 20190914_06:03 & 40,7220 & 32,9483 & $4,8(\mathrm{Mw})$ & 6 & 92 \\
\hline 20191110_10:11 & 39,7923 & 32,9523 & $3,4(\mathrm{Mw})$ & 17 & 21 \\
\hline 20200107_05:01 & 40,1191 & 33,2776 & $3,8(\mathrm{Mw})$ & 7 & 50 \\
\hline 20200123_03:54 & 40,1158 & 33,2610 & $4,5(\mathrm{Mw})$ & 14 & 49 \\
\hline 20210110_19:53 & 40,0418 & 33,323 & $4,5(\mathrm{Mw})$ & 13 & 50 \\
\hline
\end{tabular}

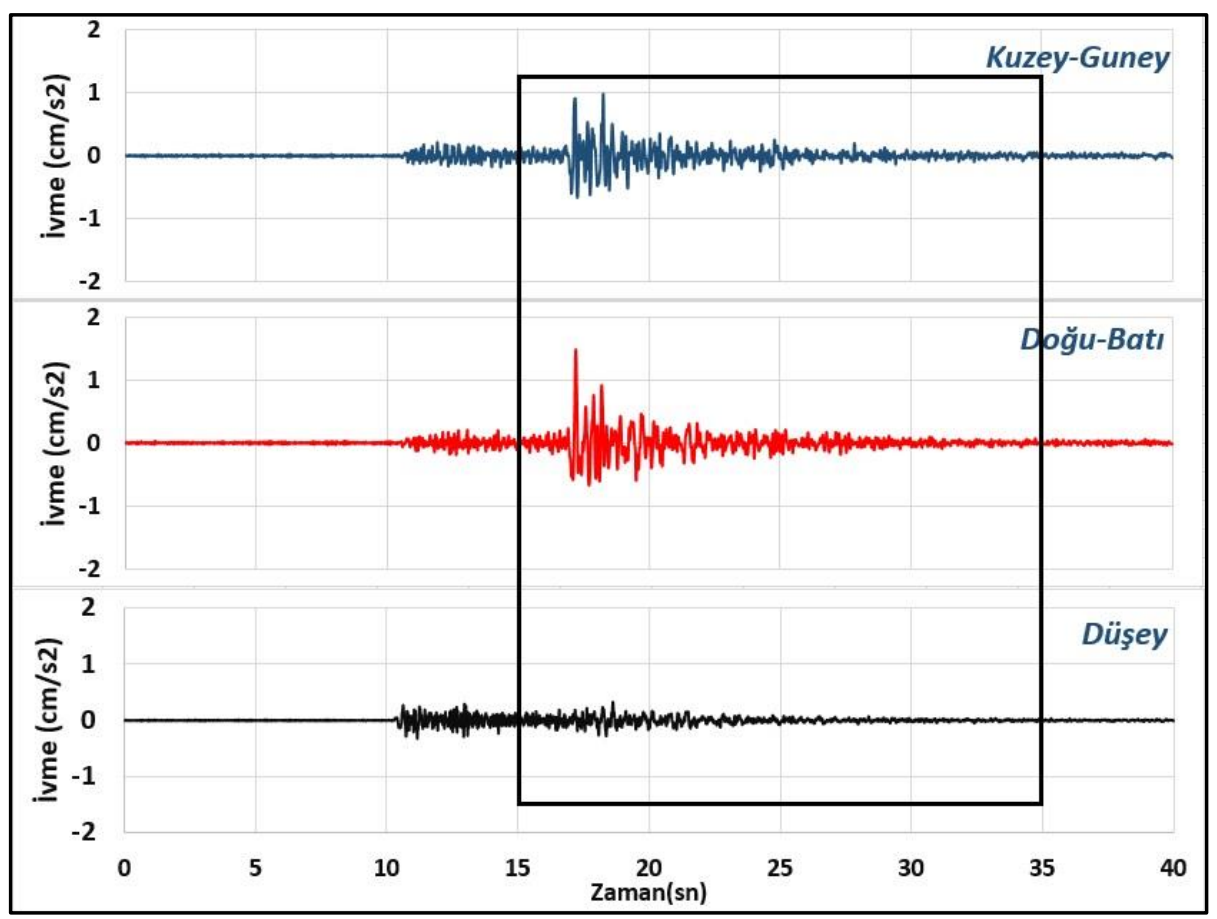

Şekil 7: 20190628 tarihinde meydana gelen depremin ivme kaydı, siyah dikdörtgen alan seçilen S dalga fazını gösterir

Çalışılan 14 adet depremin sonuçları şekil 8'de gösterilmiştir. Her bir depreme ait sonuçlar ayrı ayrı gösterilmeye çalışılmış, şekil 10'de ise depremlerin ortalama sonucu gösterilmiştir. Tüm kayıtlarda 0,81 Hz frekansında ani pik göze çarpmaktadır. Ortalama büyütme faktörü değeri 5,5 kadardır. Bu değerin yer baskın salınım frekansı olduğu sonucuna varılmıştır. Bu değerler göz önüne alındığında Rodrıguez-Marek tarafından önerilen zemin sınıflama (Rodriguez-Marek vd. 2001) tablosuna (Tablo 3) göre D2 grubu bir zemin olacağ görünmektedir. 


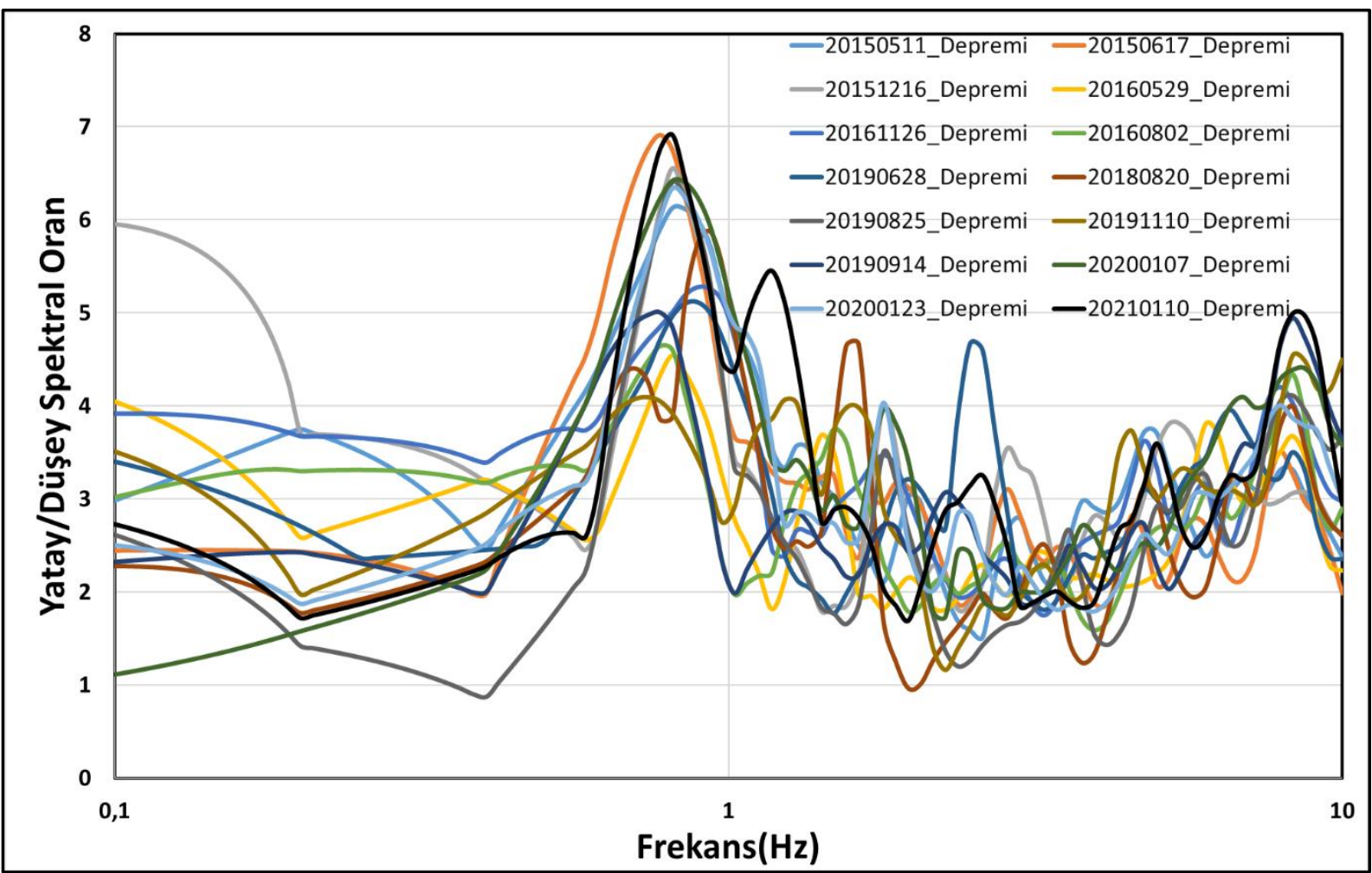

Şekil 8: Deprem kayıtlarından elde edilen HVSR analizi sonuçları

Tablo 3: Rodriguez-Marek vd. (2001) tarafından hakim frekans değerlerine göre önerilen zemin sınıflaması (Gök (2011) tarafından Türkçe'ye çevrilmiştir)

\begin{tabular}{|c|c|c|c|}
\hline Zemin & Zemin Tanımı & $\begin{array}{l}\text { Hakim } \\
\text { Frekans }\end{array}$ & Yorum \\
\hline A & Sert Kaya & $\mathrm{f0}>10 \mathrm{~Hz}$ & Sert sağlam bozumlamıș kaya $V_{s}>1500 \mathrm{~m} / \mathrm{s}$ \\
\hline $\mathrm{B}$ & Kaya & $\mathrm{f} 0>5 \mathrm{~Hz}$ & Aşınmamış kaya, $<6 \mathrm{~m}$ zemin derinliği $\mathrm{Vs}_{\mathrm{s}}>760 \mathrm{~m} / \mathrm{s}$ \\
\hline $\mathrm{C} 1$ & Aşınmış/Yumuşak Kaya & $\mathrm{f} 0>2,5 \mathrm{~Hz}$ & $\begin{array}{c}\text { Aşınmış zon, }>6 \mathrm{~m} \text { ve }<30 \text { zemin derinliği }(360<\mathrm{Vs} \\
<760 \mathrm{~m} / \mathrm{s})\end{array}$ \\
\hline $\mathrm{C} 2$ & S1 ̆g s1k1 zemin & $\mathrm{f} 0>2,0 \mathrm{~Hz}$ & Zemin derinliği $(\mathrm{h}): 6 \mathrm{~m}<\mathrm{h}<30 \mathrm{~m}$ \\
\hline $\mathrm{C} 3$ & Orta derinlikli sıkı zemin & $\mathrm{f} 0>1,3 \mathrm{~Hz}$ & Zemin derinliği (h): $30 \mathrm{~m}<\mathrm{h}<60 \mathrm{~m}$ \\
\hline D1 & $\begin{array}{l}\text { Derin sık1 Holosen yaşlı zemin, } \\
\text { kum ve kil olabilir }\end{array}$ & $\mathrm{f} 0>0,7 \mathrm{~Hz}$ & Zemin derinliği (h): $60 \mathrm{~m}<\mathrm{h}<200 \mathrm{~m}$ \\
\hline D2 & $\begin{array}{l}\text { Derin s1k1 Pliyosen yaşlı zemin, } \\
\text { kum ve kil olabilir }\end{array}$ & $\mathrm{f} 0>0,7 \mathrm{~Hz}$ & Zemin derinliği (h): $60 \mathrm{~m}<\mathrm{h}<200 \mathrm{~m}$ \\
\hline D3 & Çok derin sık1 zemin & $\mathrm{f} 0>0,5 \mathrm{~Hz}$ & Zemin derinliği (h): $\mathrm{h}>200 \mathrm{~m}$ \\
\hline E1 & Orta derin yumuşak kil & $\mathrm{f} 0>1,4 \mathrm{~Hz}$ & Yumuşak kil seviyesinin derinliği (h): $3 \mathrm{~m}<\mathrm{h}<12 \mathrm{~m}$ \\
\hline E2 & Derin yumuşak kil seviyesi & $\mathrm{f} 0>0,7 \mathrm{~Hz}$ & Yumuşak kil seviyesinin derinliği (h) $h>12 \mathrm{~m}$ \\
\hline $\mathrm{F}$ & $\begin{array}{c}\text { Özel, örneğin olası sıvılaşabilir kum } \\
\text { veva turba }\end{array}$ & $\mathrm{f} 0=1,0 \mathrm{~Hz}$ & $\begin{array}{c}\text { Sığ su seviyesi tablasına sahip, holosen yaşlı gevşek } \\
\text { kum veya organik turba }\end{array}$ \\
\hline
\end{tabular}

\subsubsection{Mikrotremor kayıtlarına uygulanan HVSR Yöntemi}

Mikrotremor verilerinin toplanmasında GÜRALP CMG 6TD marka hızölçer sismometre kullanılmıştır. Zeminde toplam 4 saat 45 dakika mikrotremor ölçümü kaydı saniyede 100 örnek olacak şekilde alınmıştır. Toplanan kayıt Geopsy programında analiz edilmiştir. Verilerde trend analizi yapılmış, band geçişli filtre uygulanmış $(0,1-25 \mathrm{~Hz})$, veriye başından ve sonundan kosinüs törpü (\%5) yapılmış ve uygun pencereler seçilmiş, her pencere için Hızlı Fourier Dönüşümü (FFT) uygulanmış ve her bir bileşene ait genlik spektrumları elde edilmiştir. Elde edilen spektrumlara bant genişliği $b=40$ seçilerek (Konno ve Ohmachi 1998) yuvarlatma uygulanmıştır. Son aşamada ise yatay bileşen spektrumlarının düşey bileşen spektrumuna oranlanmasıyla büyütme faktörü ve hakim frekans değerleri hesaplanmıştır. Mikrotremor kayıtlarının değerlendirilmesinde, Sesame (2004) kriterlerine uyulmuştur. 
Buna göre pencere boyu, belirgin devirlerin sayısının (hakim frekans, pencere sayısı ve pencere boyunun çarpımı) 200'den büyük olması, fo (hakim frekans) değerinin $0.5 \mathrm{~Hz}$ 'den büyük veya küçük olma durumu, yatay/düşey eğrisinin standart sapma değerlerinin belli değerlerden küçük olması kriterleri göz önüne alınmıştır. Analizde 25 sn'lik toplam 48 adet pencere kullanılmıştır. Hesaplanan hakim frekans değeri $0,85 \mathrm{~Hz}$ büyütme faktörü değeri ise 5,0'dır.

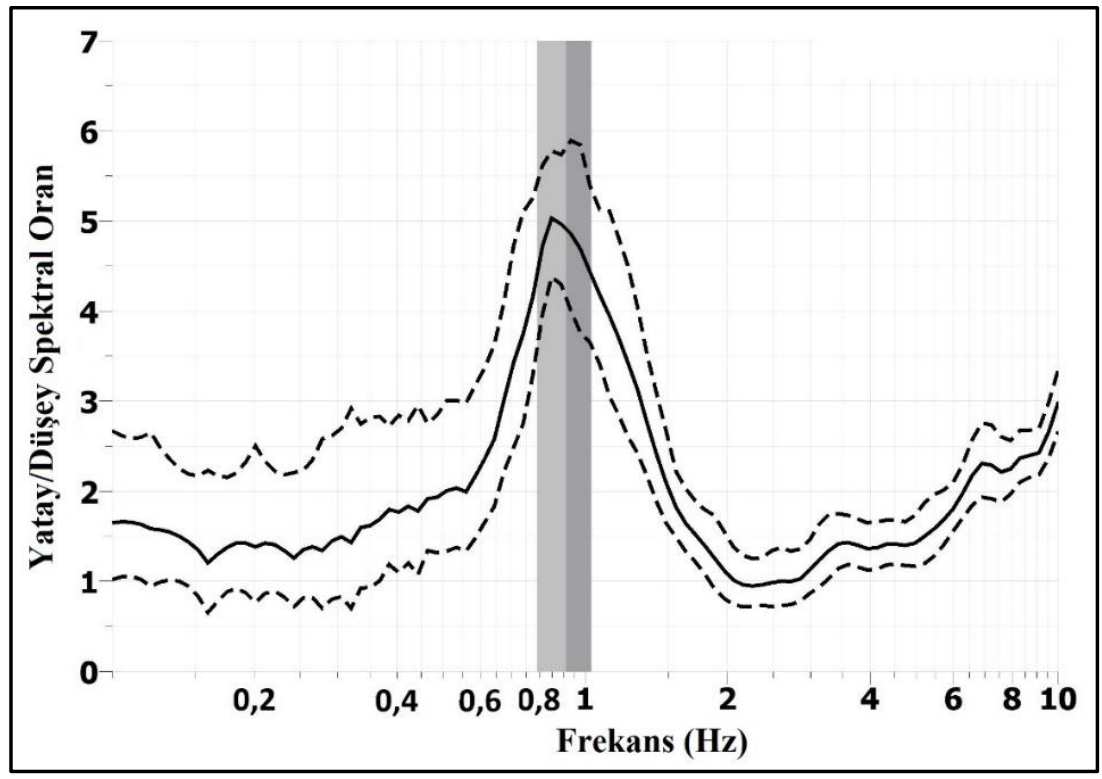

Şekil 9. Çalışma alanında kaydedilen mikrotremor kaydının HVSR analizi sonucu

\subsubsection{Deprem ve Mikrotremor kayıtlarının HVSR sonuçlarının karşılaştııııması}

AFAD kampüsü içerisinde kurulan ve bir deprem meydana geldiğinde yer ivmesini ölçmek amaciyla kurulan ivmeölçer istasyonu tarafından kayıt edilen deprem kayıtları ve zeminin dinamik özelliklerinin belirlenmesi amacıyla alınan mikrotremor kayıtlarına HVSR yöntemine göre sonuçları şekil 10' da gösterilmiştir. Şekil 10' da gösterilen deprem analizi farkı tarihlerde ve konumlarda meydana gelen 14 adet deprem kaydının ortalamasını göstermektedir. Farkı tarihlerde ve konumlarda meydana gelen 14 adet deprem kaydının ve mikrotremor kaydının HVSR yöntemine göre analizi sonucunda benzer sonuçlara ulaşılmıştır. Hakim frekansta ve büyütme faktörü değerlerinde çok az farklılıklar bulunmaktadır. Deprem kayıtlarının analizinde yaklaşık $9 \mathrm{~Hz}$ ciharında bir pik daha gözlenmiş olup bu pik mikrotremor verisinde görülmemiştir. Yalnızca deprem kayıtlarında görülen bu pikin daha derinden gelen bir etki olabileceği düşünülmektedir. Hesaplanan frekanslara göre çalışılan alanın Rodrıguez-Marek tarafından önerilen Tablo 3 'te gösterilen zemin sınıflama (Rodriguez-Marek vd. 2001) tablosuna göre D grubu (D2) grubu bir grubu olarak belirlenmiştir.

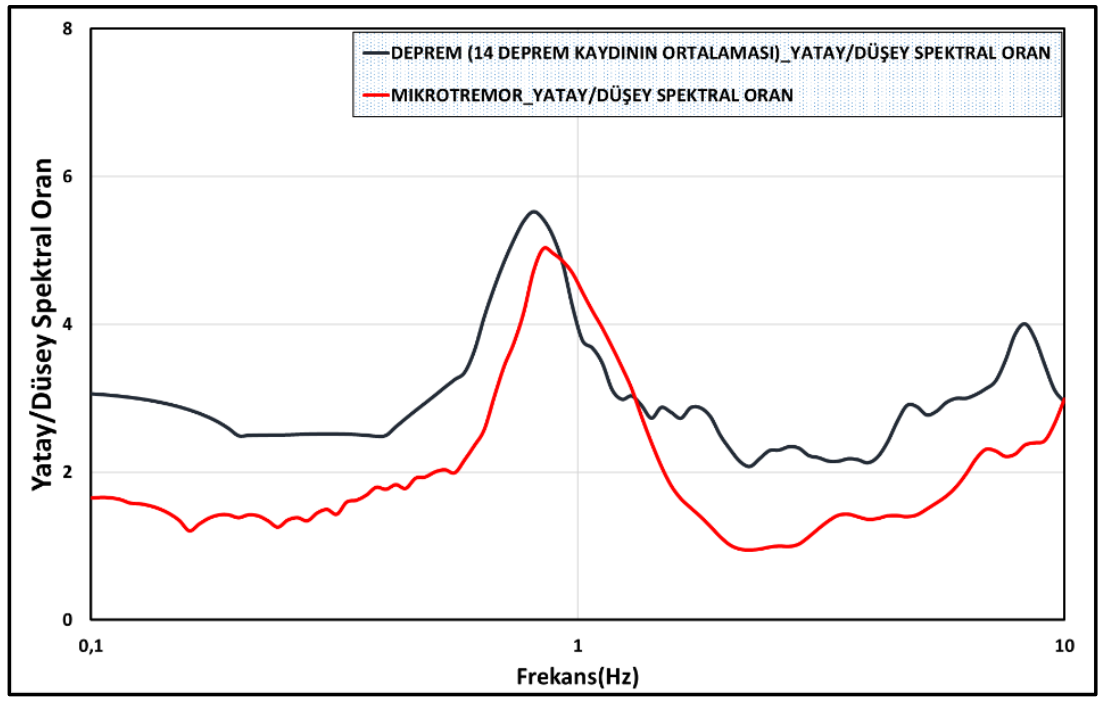

Şekil 10. Deprem ve mikrotremor kayıtlarının HVSR analizi sonuçları (Deprem kayıtlarının HVSR analizi 14 farklı deprem kaydının analizinin ortalamasıdır) 


\section{Sonuçlar}

Deprem ve mikrotremor kayıtlarının yatay/düşey spekral oran tekniğine göre analizleri sonucu bulunan zemin sınıfı ile MASW kayıtlarının analizlerinden hesaplanan zemin grubu (D sınıfi) aynıdır. Deprem ve mikrotremor kayıtlarından hesaplanan hakim frekansta ve büyütme faktörü değerleri ise birbirlerine çok yakındır. Deprem kayıtlarından hesaplanan hakim frekans $0,81 \mathrm{~Hz}$ büyütme faktörü 5,5, mikrotremor kayıtları analizinden hesaplanan hakim frekans $0,85 \mathrm{~Hz}$ büyütme ise 5,0'dır. Bu çalışmadan da görüleceği üzere derin bir alüvyon tabakası üzerinde bulunan zeminlerde yatay/düşey spektral oran tekniğinde oldukça iyi sonuçlar alınmıştır. Zemin ve yapı rezonans etkisinden uzaklaşmak için zemin hakim frekansı dikkate alınmalıdır. Özellikle 10 kat ve üzeri yapılarda yapı hakim frekansı ve zemin hakim frekansı birbiri ile rezonans oluşturabilir. Yüksek katlı yapılarda yapı frekansları zemin frekansından uzaklaşmalıdır.

MASW yöntemi sonucunda zeminin bir boyutlu kayma dalga hız profili hesaplanmıştır. İlk 30 metre kayma dalga hızı 265 m/s, 50 metreye kadar ortalama kayma dalga hızı 294 m/s olarak hesaplanmıştır. Hesaplanan bir boyutlu kayma dalga hız profili ile zeminde yapılan sondaj verileri uyumludur. Yapılan 20 metre mekanik sondajda aynı jeolojik birimler görülmüş SPT değerlerinde bir değişiklik gözlenmemiştir. Kayma dalga hızı düşük bu tür zeminlerde etkin derinlik daha yüksek olması uygun olacaktır. Zeminin ilk 30 metre kayma dalgasından ampirik formüllere göre hesaplanan göreceli büyütme değerleri yaklaşık 2,5 kattır bu ise deprem ve mikrotremor yöntemlerinden elde edilen büyütme faktörü değeri ile farklılık göstermektedir. Kayma dalgasından hesaplanan göreceli büyütme değerleri ilk 30 metre kayma dalga hızı ortalaması kullanılmaktadır deprem ve mikrotremor kayıtları ise daha derinden bilgi aldıklarından farklılık bunlardan kaynaklanabilir. Yapılan çalışmalarda aynı zeminde yapılan farklı yöntemlerin sonuçlarının birbiri ile uyumlu olduğu belirlenmiştir.

\section{Teşekkürler}

Çalışmada kullanılan deprem verilerinin toplanmasında emeği geçen AFAD Deprem Dairesi Başkanlığı personeline, değerli zamanlarını paylaşan eşim Gülten ATEŞ'e, oğlum Çınar'a, çeviri ve özet kısmındaki düzeltmeleri için arkadaşım Selim SEZER'e, mikrotremor kayıtlarının toplanmasında yardım eden Jeofizik Yük. Müh. Sami ZÜNBÜL, MASW kayıtları için Jeofizik Mühendisi Kudret TEKİN'e, genel jeoloji kısmındaki katkıları için Jeoloji Yük. Müh. Kerem KUTERDEM'e, değerli ve yapıcı eleştirileri için hakemlere sonsuz teşekkür ederim.

\section{Kaynaklar}

AFAD, (2020), Türkiye Ulusal Kuvvetli Yer Hareketi Veri Tabanı (TR-KYH), https://tadas.afad.gov.tr, [Erişim 11 Ocak 2021$].$

Akbaş B., Akdeniz N., Aksay A., Altun İ.E., Balcı V., vd., (2011), Turkey Geology Map General Directorate of Mineral Reserach and Exploration Publications, Ankara-Turkey. http://yerbilimleri.mta.gov.tr [Erişim 12 Ocak 2021].

Akkaya İ., Özvan A., (2019), Site characterization in the Van settlement (Eastern Turkey) using surface waves and HVSR microtremor methods, Journal of Applied Geophysics, 160(2019), 157-170.

Ambraseys N. N., Simpson K. U., Bommer J. J., (1996), Prediction of horizontal response spectra in Europe, Earthquake Engineering and Structural Dynamics, 25(4), 371-400.

Ateş E., Uyanık O., (2019), Jeofizik Yöntemler ile Yer ve Yapı Etkileşimi, Süleyman Demirel Üniversitesi Fen Bilimleri Enstitüsü Dergisi, 23, 46-60.

Bonilla L.F., Steidl J.H., Lindley G.T., Tumarkin A.G., Archuleta R.J., (1997), Site amplification in the San Ferdinando Valley, California: variability of site effect estimation using $S$-wave, coda, and H/V methods, Bulletin of the Seismological Society of America 87, 710-730.

Borcherdt R.D., Wentworth C.M., Janssen A., Fumal T., Gibbs J., (1991), Methodology for Predictive GIS Mapping of Special Study Zones for Strong Ground Shaking in the San Francisco Bay Region, In Proceedings of 4th Inter. Conf. On Seismic Zonation, (3), ss. 545-552.

Eker A.M., Koçkar M.K., Akgün H., (2015), Evaluation of site effect within the tectonic basin in the northern side of Ankara, Engineering Geology, 192(2015), 76-91.

Emre O., Duman T. Y., Ozalp S., Elmaci H., Olgun S., Saroglu F., (2013), 1/1.250.000 scaled Turkey active fault map, General Directorate of Mineral Research and Exploration Special Publication. http://www.mta.gov.tr/ [Erişim 01 Temmuz 2020].

Gök E., (2011), Investigation of Earthquake Hazard and Seismic Site Characteristic in The Examples of Bursa and Izmir, Doktora Tezi, DEÜ Fen Bilimleri Enstitüsü, Buca, Izmir.

Gok E., Chavez-Garcia F.J., Polat O., (2014), Effect of soil conditions on predicted ground motion: Case study from Western Anatolia, Turkey, Physics of the Earth and Planetary Interiors, 229, 88-97.

Konno K., Ohmachi T., (1998), Ground-Motion Characteristics Estimated from Spectral Ratio between Horizontal and Vertical Components, Bulletin of the Seismological Society of America, 88, 1, 228-241.

Lermo J., Chavez G. F. J., (1993), Site Effect Evaluation Using Spectral Ratios with Only One Station, Bulletin Seismological Society of America, 83, 1574-1594.

Livaoğlu H., (2015), Kocaeli-Gölcük-Değirmendere Bölgesi için Zemin Hakim Frekansl-Sediman Kalınlı̆̆l İlișkisinin ve Zemin Özelliklerinin Belirlenmesi, Yüksek Lisans Tezi, Kocaeli Üniversitesi, Fen Bilimleri Enstitüsü Jeofizik Mühendisliği Anabilim Dalı, Kocaeli.

Midorikawa S., (1987), Prediction of isoseismal map in Kanto plain due to hypothetical earthquake, Journal of Structural Engineering, 33B, 43-48. 
Nakamura Y., (1989), A Method for Dynamic Characteristics Estimation of Subsurface Using Microtremor on the Ground Surface, Quarterly Report of the Railway Technical Research Institute, 30(1), 25-33.

Nath S.K., (2007), Seismic microzonation framework-principles and applications. In Proceedings of Workshop on Microzonation, 2627 June, Indian Institute of Science, Bangalore, ss 9-35.

Ozalaybey S., Zor E., Ergintay S., Tapırdamaz M.C., (2011), Investigation of 3-D basin structures in the 'Izmit Bay area (Turkey) by single-station microtremor and gravimetric methods, Geophysical Journal International, 186, 883-894.

Özdağ Ö.C., Gönenç T., Akgün M., (2015), Dynamic amplification factor concept of soil layers: a case study in İzmir (Western Anatolia), Arab J Geosci, 8(11), 10093-10104.

Özdă̆ Ö.C., Gönenç T., (2020), Modeling stratigraphic structure of Menemen Plain-Izmir/Turkey by microgravity, passive seismic methods and examining its behavior under earthquake effect, Journal of Applied Geophysics, 182:104175, doi: 10.1016/j.jappgeo.2020.104175.

Ozer C., (2019), Erzurum ve Çevresi Yerel Zemin Etkilerinin SSR ve HVSR Yöntemleri Kullanılarak Araştırılması, DEU FMD 21(61), 247-257.

Pamuk E., Gönenç T., Özdağ A.C., Akgün M., (2018), 3D Bedrock Structure of Bornova Plain and Its surroundings (Izmir/Western Turkey), Pure Appl. Geophys. 175(2018), 325-340.

Pamuk E., (2019), Investigation of the local site effects in the northern part of the eastern Anatolian region, Turkey, Bollettino di Geofisica Teorica ed Applicata, 60(4), 549-568.

Park C.B., Miller R.D., Xia J., (1999), Multi-channel analysis of surface waves. Geophysics, 64(3), 800-808.

Rodriguez-Marek A., Jonathan D.B., Norman A.A. (2001), An empirical geotechnical seismic site response procedure, Earthquake Spectra, 17(1), 65-87.

Saraç G., (2003), Türkiye omurgali fosil yataklart (Fossil vertebrate localities of Turkey), MTA Report No 10609, 218 ss.

Sesame, (2004), Guidelines for the Implementation of the H/V Spectral Ratio Technique on Ambient Vibrations, Measurements Processing and Interpretation. Europan Research Project.

TBDY, (2018), Türkiye Bina Deprem Yönetmeliği, Resmî Gazete Tarih: 18 Mart 2018, Sayı: 30364, http://www.resmigazete.gov.tr/ eskiler/2018/03/20180318M1.pdf, [Erişim 11 Ocak 2021].

Tunçel A., Özdağ Ö. C., Pamuk E., Akgün M., (2019), Calculation of the soil dynamic amplification factor values by using microtremor data: A case study in Izmir (North), Journal of the Faculty of Engineering and Architecture of Gazi University 34(1), 43-52.

Türkmen İ., Özkul M., (1999), Sedimantology and evaporite genesis of Neogene continental sabkha playa complex, Karakeçili basin, central Anatolia Turkey, Carbonates and Evaporites, 14(1), 21-31.

Uyanık O., (2015), Deprem Ağır Hasar Alanlarının Önceden Belirlenmesi ve Şehir Planlaması için Makro ve Mikro Bölgelendirmelerin Önemi, Süleyman Demirel Üniversitesi, Fen Bilimleri Enstitüsü Dergisi, 19(2), 24-38.

Yalçınkaya, E., (2005), BYT-Net (Bursa-Yalova-Türkiye İvme Ölçer A ̆ğl) İstasyonlarında Yerel Zemin Etkilerinin İncelenmesi, Fen ve Mühendislik Dergisi, 7(2), 75-86.

Yalçınkaya E., (2010), Zemin neden bu kadar önemli, Jeofizik Bülteni, 63, 77-80. 